\title{
SOBRE UN BIFAZ CORDIFORME DEL BAJO GENIL
}

\author{
ON A BIFACIAL TOOL FROM THE LOWER GENIL VALLEY
}

\author{
por \\ ENRIQUE VALLESPÍ PÉREZ
}

La pieza que presento procede de un hallazgo casual, realizado hace unos años en la margen izquierda del Genil, cerca de la afluencia del río Cabra, y su testimonio viene a corroborar y puntualiza una presencia achelense superior avanzada y Paleolítico Medio de tradición achelense genérica en dicho ámbito local.

El lugar del hallazgo corresponde a una finca de Las Mesas o La Isla, junto al poblado de La Montiela, en el término municipal de Santaella (Córdoba), lindante con el de Ecija (Sevilla). La pieza en cuestión fue recogida por María José Chic García, estudiante entonces (mayo de 1987) de $7^{\circ}$ curso de EGB, pasando a mi conocimiento por mediación del padre de la niña, Genaro Chic, amigo y compañero en la Facultad de Geografía e Historia de la Universidad de Sevilla. Con dicha pieza se recogieron también, en el área del hallazgo, varios restos líticos de talla y un resto óseo humano (parte de fémur). Sin revisión directa de campo, presento ahora el bifaz, siguiendo mi atención a este tipo de piezas que, en su tipología clásica, pueden suponer alguna puntualización a las atribuciones de datación arqueológica de la secuencia del Bajo Guadalquivir, de la que sistemáticamente nos estamos ocupando. El bifaz que analizo está obtenido en soporte de canto rodado de sílex, posiblemente en una lasca, aunque no queda ningún accidente de la talla como tal; de grano muy fino y color marrón claro en su interior, las aristas de la talla bifacial aparecen con redondeamiento leve y la pátina recubre ambas caras de forma desigual, con la considerada inferior suavizada en beige y la superior ocre, propia de arenero, de cuya matriz conserva la pieza diversas adherencias; presenta dos desconchados distales, uno semipatinado en la cara inferior y otro actual en la superior, que deja al descubierto la materia prima inalterada y el espesor (de $1 \mathrm{~mm}$. aproximadamente, en apreciación visual) blanquecino -lechoso de la película de pátina, superficialmente ocre. La talla bifacial, talón exceptuado, diferenciada también en ambas caras; el aparente aspecto levallois de la inferior no es sino de lascado basal profundo de adelgazamiento, con sobreimposición de los lascados centrípetos del contorno; la superior, de levantamientos más planos, centrípetos y cubrientes. De sección aceptablemente biconvexa y aristas de los bordes algo retocadas en su mitad distal, rectilínea la derecha y sinuosa la izquierda y ambas con mataduras presumiblemente de uso. Sus medidas son: $L=78 \mathrm{~mm}$., $\mathrm{m}=57, \mathrm{a}=23$, $\mathrm{n}=51, \mathrm{o}=32$, e=25 mm., por lo que, por sus índices es de silueta cordiforme ( $\mathrm{L}: \mathrm{a}=3,39 ; \mathrm{n} .100: \mathrm{m}=89,47$; banda III), plano ( $\mathrm{m}: \mathrm{e}=3,12>2,35$ ) y corto $(\mathrm{L}: \mathrm{m}=1,36<1,5)$, resultando, por lo tanto, un bifaz cordiforme con talón, de cierta tendencia a triangular. 
La atribución tipológica de este bifaz a una línea achelense avanzada y de perduración en el Paleolítico Medio se refuerza además teniendo en cuenta su procedencia de la terraza del Genil relacionada con los niveles bajos del Guadalquivir, con los que debe correlacionarse el depósito originario de la pieza en cuestión, cuyas partículas de matriz podrán ayudar a determinar su correlación precisa y, por ende, su definitiva atribución.

Estratigráficamente, en la secuencia del Bajo Guadalquivir esta línea del Achelense Final transicional y de un Paleolítico Medio arqueológicamente postachelense corresponde a los niveles T12 y T13, que aparecen precedidos por el Achelense Pleno avanzado de T11 y los testimonios iniciales anteriores, por ahora culturalmente indeterminados, desde los niveles T6 que comienzan los registros de momento disponibles (Díaz del Olmo, Vallespí, Baena, 1993; Vallespí, 1993).

Conviene señalar que este planteamiento de una línea achelense avanzada y Paleolítico medio atañe en principio a la dificultad de clasificación cultural precisa de determinados conjuntos, no sólo procedentes de superficie sino también alguno del interiorde depósitos sin posición cronoestratigráfica sificientemente aclarada; los conjuntos en cuestión presentan un bloque macrolítico de cantos tallados, bifaces (con ejemplos de formato grande), hendedores y triedros, de aspecto ínferopaleolítico, junto a un desarrollo significativo de los grupos levallois, musteriense y paleolítico superior, de aspecto avanzado en estas series. Pero considero también que la razón última de esta imprecisión atributiva puede radicar, y así lo pienso, en la misma realidad de la existencia de un continuum tecno-tipológico de las industrias en los niveles secuenciales implicados, cuya hipótesis he pretendido plantear para este espacio regional y propuesto para más amplia escala peninsular (Vallespí, 1988 y 1989).

En relación con esta problemática y vertebración estratigráfica, la dispersión de los hallazgos de bifaces tipológicamente indicativos de la línea de continuidad achelense avanzado y final y Paleolítico Medio postachelense está plenamente comprobada en la Depresión Inferior del Guadalquivir con los registros que ya disponemos de bifaces amigdaloides cortos y cordiformes (con tendencia triangular y algún triangular inédito) conforme a la relación establecida (Vallespí, Escacena, Ramos Muñoz, 1992; con las referncias bibliográficas pertinentes) de los testimonios del mismo Bajo Guadalquivir (Arroyo de Ventogil, en Córdoba; Villaesparra, La Celada, Tarazona, Arroyo Trujillo, en Sevilla), del bajo Tinto y litoral de Huelva (El Monturrio, La Dehesa, La Antilla), del Guadalete inferior y litoral de Cádiz (Laguna de Medina y La Barrosa) y del tramo subbético exterior occidental (Los Corrales, en la Sierra Sur de Sevilla). A estos testimonios anteriormente aducidos, a los que se une el nuevo ejemplar cordiforme que ahora publico, puedo añadir las noticias de otros dos bifaces del mismo tipo cordiforme con tendencia triangular, del curso medio del Corbones, en el mismo foco local del nuevo hallazgo, inéditos y en estudio por J.J. Fernández Caro, entre los densos conjuntos de estas series de su tesis doctoral, y de un ejemplar de aspecto triangular, pediente de análisis, del Guadalquivir (loc. Sinergiprón) en Sevilla, recordando también que del mismo término municipal del nuevo hallazgo del bajo Genil hay un bifaz de aspecto micoquiense, entregado para su publicación hace unos años (Vallespí, Cruz-Auñón, Rivero, e.p.), lo que densifica aún más las evidencias del achelense avanzadas y de su tradición en el Paleolítico Medio en la Depresión Inferior del Bajo Guadalquivir.

\section{REFERENCIAS BIBLIOGRÁFICAS:}

DÍAZ DEL OLMO, F.; VALLESPÍ, E.; BAENA, R. (1993): «Cuaternario y secuencia paleolítica en las terrazas del bajo y medio Guadalquivir: aluvionamientos, coluviones, suelos y paleosuelos», Investi- 
gaciones Arqueológicas en Andalucía, 1985-1992. Proyectos: 193-210, Junta de Andalucía, VI Jornadas de Arqueología Andaluza, Huelva.

VALLESPÍ, E. (1988): «Paleolítico Medio de aspecto postachelense en la Depresión Inferior del Guadalquivir», Espacio, Tiempo y Forma, serie I, Prehistoria t. 1, Homenaje al Prof. E. Ripoll Perelló; 85-91, UNED, Madrid.

(1989): «Paleolítico Medio indeterminado, de aspecto postachelense, en los ámbitos fluviales del sur y centro de la Península Ibérica», Veleia 6: 7-20, Universidad del País Vasco, Vitoria.

(1993): «El Bajo Guadalquivir en el Peleolítico Inferior y Medio peninsular», Altamira Monografías $\mathrm{n}^{\circ}$ 17: 1-9, Museo y Centro de Investigación de Altamira.

VALLESPÍ, E.; ESCACENA, J.L.; RAMOS MUÑOZ, J. (1992): «Un bifaz de La Barrosa, del Achelense Superior o su tradición inmediata, del frente atlántico andaluz», Cuadernos del Suroeste 3: 115-123. Museo de Huelva.

VALLESPÍ, E.; CRUZ-AUÑÓN, R.; RIVERO, E. (1988): «Paleolítico Medio de aspecto postachelense en la Depresión Inferior del Guadalquivir», Espacio, Tiempo y Forma, serie I, Prehistoria t. 1, Home 

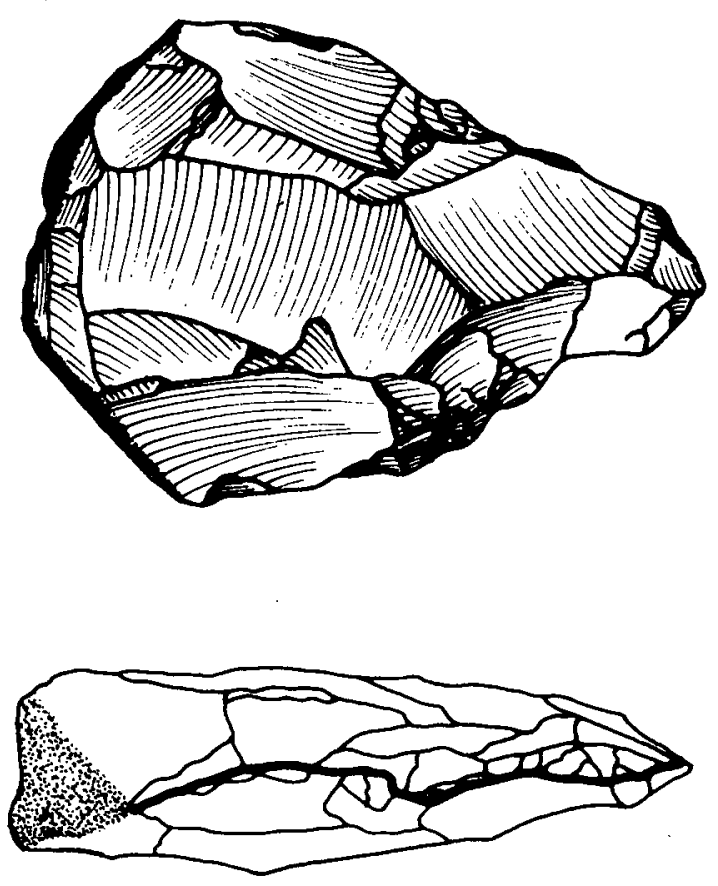

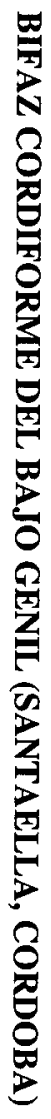
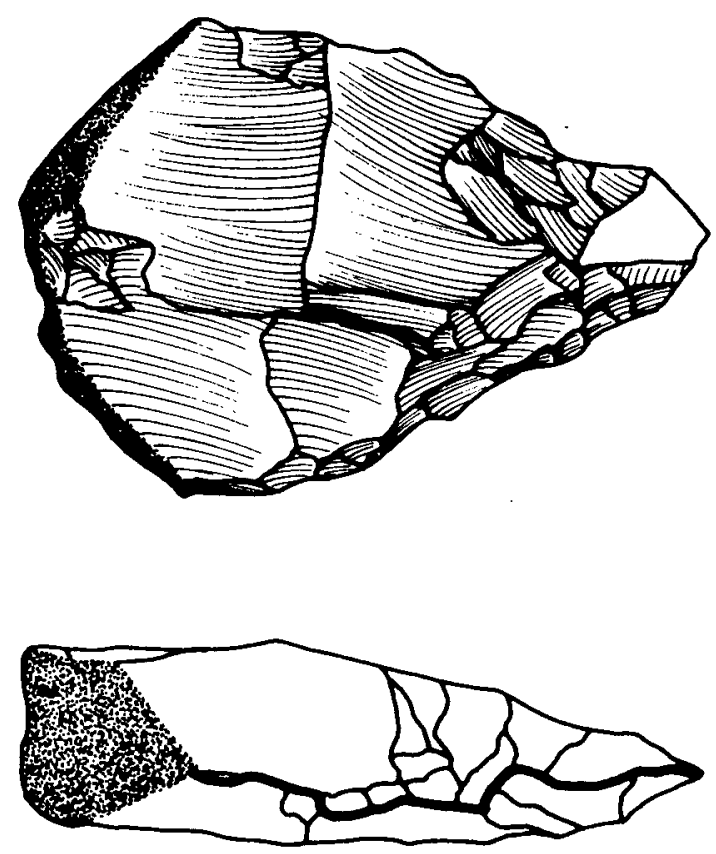